\title{
Fine Motor Functioning and Perception in Children with Tourette Syndrome
}

\author{
Najah Khalifa ${ }^{1,2 *}$ and Solwig Eklund ${ }^{3}$ \\ ${ }^{1}$ Department of Child and Adolescent Psychiatry, Institution of Neuroscience, Uppsala University, Uppsala, Sweden \\ ${ }^{2}$ Centre for Research and Development, Uppsala University/Region Gävleborg, Sweden \\ ${ }^{3}$ Habilitation Centre Dalarna, Sweden
}

* Corresponding author: Najah Khalifa, Department of Child and Adolescent Psychiatry, Uppsala University, SE-751 85 Uppsala, Sweden, Phone: +46 736637601; E-mail: najah.khalifa@regiongavleborg.se

Received date: Sep 15, 2017; Accepted date: Oct 13, 2017; Published date: Oct 19, 2017

Citation: Khalifa N, Eklund S (2017) Fine Motor Functioning and Perception in Children with Tourette Syndrome. J Child Dev Disord. Vol 3. No 4: 18.

Copyright: (C) 2017 Khalifa N, et al. This is an open-access article distributed under the terms of the Creative Commons Attribution License, which permits unrestricted use, distribution, and reproduction in any medium, provided the original author and source are credited.

\section{Abstract}

Aim: The aim of this study was to describe the motor function and perception in a children with Tourette syndrome.

Method: Twenty three children aged 7-15 years old with Tourette syndrome. Interview and clinical observation were used.

Results: A third of the children display fine hand motor impairment, decreased psychomotor speed and handwriting deficits. In addition, half of the children have difficulties in planning and remembering exercises. Many children with Tourette syndrome need help with activities of daily living (ADL). The children with Tourette syndrome differ significantly in visual -spatial- motor organisation and visual- and auditive perception.

Conclusion: Tourette syndrome seems to associated with fine motor, perception problem. Early interventions to help with fine motor skills of TS symptoms should be undertaken, and in view of TS children, interventions such as an occupational therapist appear necessary.

Keywords: Child/Adolescents; Fine and gross motor development; Perception

\section{Introduction}

Tourette syndrome (TS) is a neurologic disorder as well as features that are now associated with behavioural problems. The marked are fluctuations in the severity and a frequency of symptoms. The pathophysiology of TS has been associated with dysfunction of the basalganglia and related thalamocortical circuits $[1,2]$. Comorbid disorders include attention deficit/hyperactivity disorder (ADHD), obsessivecompulsive disorder (OCD), mood disorders, executive function deficits, and other problems are common as well $[1,3]$. Many children with TS will need special-education facilities [3-5]. Previous studies have reported that children and adults with TS have difficulties in fine-motor, perceptual and visual motor skills [4-14], although one study reported no impairment [15]. Furthermore, some of these studies have indicated that patients deficits are unlikely to be due to comorbid ADHD [6,7]. Harris et al. [12] found evidence for a deficit in children with TS and comorbid ADHD, but not in those with TS only. In contrast, another study [10] showed that TS patients without ADHD exhibited impairment similar to the impairment exhibited by those with comorbid ADHD. Korsgaard [13] has described that $25 \%$ of children with TS have learning difficulty, the problems among other describe are defective eye-hand motor, defective visual-motor control, defective ability of adapting to complex tasks, problems with visual memory and problems of balance and coordination. Children with TS almost universally experience problems with written expression. Jewers [14] described that children with TS often display fine motor impairment, decreased psychomotor speed, handwriting deficits, visuomotor integration problems, and spatial organisational deficits. Bloch et al. [6] reported that fine motor skill deficits might be predictors of future tic severity and global psychosocial function in children with TS. Britta Holle [16] describes children's normal fine-motor development and she emphasizes that it is important for development that the motor perceptual progress is studied during the children's development. Eye- hand coordination, tactile senses and the kinetic senses also have to follow the development and influence fine-motor skill. At six to seven years of age most children have well-developed fine-motor ability.

Therefore it is important to know which difficulties and which strengths children with TS have in order to help them early. The object of this study is to survey the perception, hand function and the motor function in children with TS. 


\section{Methods}

\section{Participation}

Participants included 23 children's with TS, at the age of 7-15 years, two girls and 21 boys were examined by the first author (child neurologist) and by an occupational therapist. Eighteen children who had gross motor difficulties at the neurological examination were also examined by a physical therapist.

\section{Procedure}

The children were called by a letter sent to each home for a medical examination and a testing by an occupational therapist. These took place at different times. They were with either parents or parents with an assistant or a teacher. The children could choose if they wanted to have the adults in the examination room. Agreements from the parents were collected at the same time that the children were selected for the study. All 23 were medically examined by the first author, two children by another child neurologist and child psychiatrist. The occupational therapist (second author) made the hand function and perception test of 17 of the 23 children. The other six had recently been examined by another occupational therapist; therefore some of the results which were found in the journal at the habilitation were used instead. Information about the children's conditions and needs were obtained from parents and the school. The occupational therapist test took about 1.5 hours during which time the child performed tasks according to instructions for the respective instrument. The test was filmed with a video camera. Five children declined to be filmed. The videotapes were analysed. In connection with the testing of the children, an observation was also done. The results were complied and the children who had unsure gross motor function were also tested by a physical therapist, they were 18 children.

\section{Physical examination}

The Physical examination was comprised of a routine paediatric examination weight, height and head circumferences were measured. Evaluation of the child's general condition, speech, language, activity level, skull, mouth, lungs, heart, blood pressure, abdomen, skin and puberty stage, as well as minor physical anomalies (MPA) were scored in accordance with Waldrop and Halverson [17]. A more detailed neurological and mental examination was carried out using a modified version of the neurodevelopmental screening test [18]. The examination included the testing of cranial nerves, finger-nose, fingerfinger, knee-heel test, Romberg's- and Prechtel's test. Crosscountry ski jump, jumping back and forth across a line, standing on left and right leg for 20 seconds, walking on heels and toes and the Fog's. Hopping 10 hops on one foot, sensation, diadochokinesis, and stereognosis as well Babinski and deep tendon reflexes and tone too. Each of the items was scored on a scale from 0 to 2 ( 0 - no abnormality, 1 - some abnormality and 2 - major abnormality) Table 1.

Table 1. Physical and neurological assessment.

\begin{tabular}{|c|c|}
\hline Item & Comment \\
\hline General physical examination & $\begin{array}{l}\text { Weight, height, head circumference, speech, } \\
\text { language, activity level, skull, mouth, lungs, } \\
\text { heart, blood pressure, abdomen, } \\
\text { skin and puberty stage }\end{array}$ \\
\hline \multicolumn{2}{|l|}{ Minor physical anomalies (MPA) } \\
\hline \multicolumn{2}{|l|}{$\begin{array}{l}\text { Neurological test } \\
\text { 1-Cranial nerves }\end{array}$} \\
\hline 2- A portion of Folke Bernadotte test & (fine motor skill) \\
\hline \multicolumn{2}{|l|}{ 3-muscle tonus } \\
\hline \multicolumn{2}{|l|}{ 4-Finger-nose } \\
\hline 5-Romberg test & (standing with feet together and eyes closed) \\
\hline 6-Stereognosis & Figures drawn in child's palm \\
\hline \multicolumn{2}{|l|}{ 7-Prechtl test } \\
\hline 8-Diadochokinesis & Each hand tested separately for 10 seconds \\
\hline \multicolumn{2}{|l|}{ 9-Standing 20 seconds on each leg } \\
\hline \multicolumn{2}{|l|}{ 10- Jumping back and forth across a line } \\
\hline 11-Walking on heels & \\
\hline
\end{tabular}




\begin{tabular}{|l|l|}
\hline $12-$ Walking on toe & \\
\hline $13-$ Fogs test & Walking on outer sides of feet \\
\hline $14-$ Catch a ball & \\
\hline $15-$ Tendon reflexes & \\
\hline $16-$ Babinski sign & \\
\hline
\end{tabular}

\section{Assessment of fine motor skills and perception}

The Assessment of fine motor skills and perception included 14 testing criteria :

Pen holding

Pressure with the pen

Body position

Finger manipulation

Eye-hand coordination

Auditive perception

Visual perception

Planning, memory

Spatial perception, room concept

Concentration, attention, stamina

Hand dominance

Hand strength

Quickness

Sensibility

The suitable, standardized assessment measures that were used are presented below. For some of the criteria, observations documented in the children's journals were more suitable. The information was summarized and compared with the instrument's norms to tell if the child solved the problems or not. The descriptive conception of the child's strengths and weaknesses are translated to Luria's terminology in accordance with the concept of the occupational therapists who work with cognitive rehabilitation [19].

\section{Assessment Measures}

\section{HABBA}

A Swedish instrument, HABBA (Table 2), for investigating hand function in children, has been developed with normative data for children between six and twelve years of age. The HABBA instrument consists of tests which can identify motor, sensory, kinaesthetic functions and visual perception. The theoretical frame of reference for this instrument originates from Luria's neuropsychological theory. Luria describes function as a complex activity [19]. Each performance or activity such as speaking, writing or other motor activities is regarded as a functional system that engages many different processes. These processes are based on specific tasks which determine the scheme for the continuation of the action, and they are supported by utilisation of complicated and variable modes of behaviour. The HABBA instrument is based on three different tests from Luria's neuropsychological investigation: motor functions, sensory - kinaesthetic functions and visual perception. These components are important for the child when learning how to use his or her hands in different activities. The development and co-ordination of these functions must be successfully achieved to allow the child, when adult, to perform more difficult cognitive tasks. In 1964, Liorens et al. [20] described how children with cognitiveperceptual-motor difficulties could develop an incapacity to handle different activities in daily life and an incapacity to meet the demands of the environment. Reliability and validity of the HABBA have been evaluated in Sweden [21]. The children who were judged with the HABBA method were filmed on video and the video was analysed. The results were compiled and documented in the children's journal. The tasks in every group were summarized and compared with the norm group's results. This comparison tells whether the children successfully did the tasks or not.

Table 2: The instrument HABBA.

\begin{tabular}{|c|c|}
\hline Areas of investigation & $\begin{array}{l}\text { Tasks } \\
\text { (No.) }\end{array}$ \\
\hline \multicolumn{2}{|l|}{ 1- The motor functions of the hands } \\
\hline Simple movement & 3 \\
\hline Optic-spatial organisation of the motor act & 10 \\
\hline The dynamic organisation of the motor act & 11 \\
\hline Complex forms of praxis & 15 \\
\hline Optic-motor organisation & 3 \\
\hline Peg-board, right hand & 1 \\
\hline Peg-board, left hand & 1 \\
\hline Acoustic-motor organisation & 2 \\
\hline \multicolumn{2}{|c|}{ 2- Cutaneous sensation, muscle and joint sensation and Stereognosis } \\
\hline Tactile sensation & 6 \\
\hline Tactile discrimination & 2 \\
\hline Tactile localisation & 9 \\
\hline Tactile spatial discrimination & 2 \\
\hline Tactile identification of the direction of movement & 6 \\
\hline
\end{tabular}




\begin{tabular}{|l|l|}
\hline Kinesthetic sensation & 17 \\
\hline Stereognosis & 9 \\
\hline 3- Higher visual function & 14 \\
\hline Perception of pictures & 9 \\
\hline Spatial orientation & 7 \\
\hline Intellectual operations in space & \multicolumn{2}{|l|}{} \\
\hline
\end{tabular}

\section{Vigorimeter"Martin"}

This instrument measures hand strength when a person squeezes a ball, which is connected by a tube to a dynamometer, which shows the result on a scale in Kpa bar. There are three sizes of balls; the medium ball is recommended for children at the age which is included in this study and connected to norm values [22].

\section{Fine-motor development status}

Fine-motor development status is compiled by the occupational therapists Lantz and Melén [23]. The status describes the fine-motor development in activities such as drawing and cutting among others in children at the age of 1-7 years. It measures not only the child's hand motor but also how the child accomplishes fine-motor activities, which is an interplay between the hand's motor, rough-motor function, eye movements, perception and cognition. Certain activities are more completely fine motor than others, for example how the child holds the pen. The instruments are based on Holles [16] description of the hand's motor developments.

\section{In-hand manipulation}

This instrument shows how manipulation develops in children. The instrument was the basis for result recording in the ability to manipulate [24]. The ability to adjust handgrip and move an object in the hand is named" in hand manipulation" a concept defined by the American occupational therapy.

\section{Observation during activities}

The observations were done during the testing period and based on the testing criteria, which were presented earlier. The observation is widely based on earlier experiences from examinations of children and youths with fine motor problems. It is also based on information from the children and the accompanying relative during the testing.

\section{Ethic}

The Ethics Committee of the Faculty of Medicine at Uppsala University approved the study.

\section{Statistics}

The statistical package of SPSS for Macintosh 10.0 was used. Comparisons of proportions between groups were performed using chi-square-tests. Comparisons of mean values were performed with ANOVA. Pearson's correlation coefficient was used to examine the linear association between variables. A significance level of $5 \%$ was used.

\section{Results}

\section{Neurological examination and gross motor function}

Twenty percent of children with TS displayed developmental coordination disorder. $36 \%$ of the children had some reduced tonus. $30 \%$ of the children had difficulty with diadokokineses. $12 \%$ of the children had difficulty hopping up and down on one leg. $30 \%$ of the children had difficulty with running and then stopping, and $16 \%$ of the children had a little difficulty with the Fog test and had difficulty with catching a ball. $10 \%$ of the children are left-handed and three had difficulty with the $\mathrm{FBH}$ task. MPA is pathological in $10 \%$ of the children. $16 \%$ children have pathological movement $A B C$ Test.

\section{Fine motor skills and perception}

Most children were right handed (70\%), one tenth were lefthanded whereas $20 \%$ used interchangeable right and left hand in different activities. For example, they write with their left hand and eat with their right and sometimes interchange these in the activities. Not many children have problems with hand strength, sensibility or finger manipulation. The majority of the children (52\%) have visual perception difficulties, i.e. understanding and adapting visual information. They have difficulty in retaining and recreating information. Abstract pictures are more difficult to understand for children than concrete ones and some children need extra time to interpret pictures. Almost half of the children (48\%) also have difficulties in planning and remembering performed exercises. They have difficulty in looking at a picture and recreating it by memory. Other problems relate to body positioning and quickness. The children's body position was observed during the time they worked with the tasks. Some of them (16\%) moved around on their chairs and slid down without correcting themselves back into a good position whereas the others move around on their chairs more or less during the whole investigation but could correct themselves back into a good position. It could be seen that $42 \%$ of the children have a need to fidget in their chairs when they are doing their exercises. Many children are less quick in fine motor tasks than normal children. When they pick up sticks one with each hand at a time during the stick test, $40 \%$ of the children need longer time than the average for their age.

Concentration, attention, stamina are the other areas that cause problems. Many children (40\%) have difficulty in concentrating during the whole assessment. Due to decreased stamina, it is easier for them to concentrate, when there is only one task presented at the time. Some show tiredness at longer tasks such as the stick test and some need to rise and go around between each task. One child fidgets on the chair but is still attentive to the instructions and can return to the task by himself. 
A quarter of the children have difficulty with auditive perception (24\%). One child could not listen to knocking on the table and then repeat the same sound. One fifth (20\%) cannot listen to three instructions in a row and then perform the activities which were given. One child began to do the last instruction given but could not remember the earlier instructions. Two children were disturbed by sounds outside the room at the time of the investigation. One child says that he is disturbed by the noise in the classroom.

One third of the children (28\%) do not have an adequate pen grip. They hold a pen in various ways and sometimes revert to holds that younger children use in their development. Two older children, 13 and 16 years of age, have completely deviating grips. One child holds the pen, so hard that his knuckles become pale. One tenth of the children use more pressure when they hold the pen to the paper but the majority do not apply a noticeable pressure when they hold the pen to the paper to write and draw.

A fifth of the children have a reduced ability in eye-hand coordination. The two younger children, nine and eleven years of age, have difficulty in hand /finger activities while the two older youths 14 and 16 years of age are affected when visual elements increase in the activities. They need time for visual interpretation.

One third of the children have difficulties with the spatial perception. The difficulties may be to place the objects in the same position as shown on a picture. Most of the children (95\%) have adequate hand strength according to the measurements with the dynamometer. Most of the children (95\%) can identify and manipulate object in their hands (Figure 1).

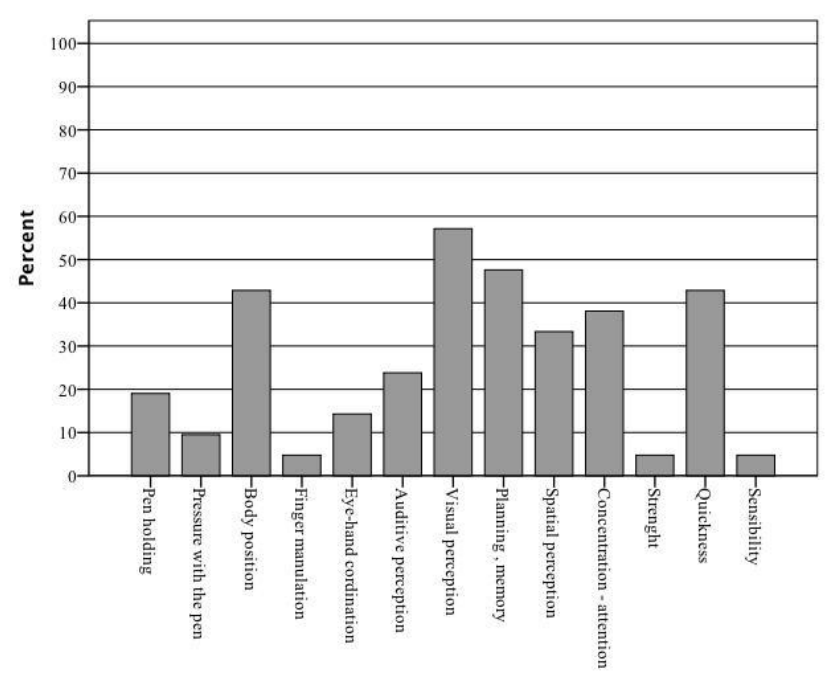

Figure 1: Percentage of children with TS showing impairment in each triad area.

Activities in daily living

This relates to the children's independence and their need for assistance in the different areas. 39\% need help with activities of daily living (ADL), for example dressing, assistance with time, and showering.

\section{Discussion}

Fine motor and perception difficulties may be common in children with Tourette syndrome. The most important findings were that many children (40\%) with TS need help with activities of daily living (ADL). In Hubka et al. [25] study examining Tourette's syndrome within the family, $58 \%$ of respondents indicated that the condition interfered to some degree with their daily lives. In this study, children often had difficulties with body position and have needed to fidget in their chairs when they are doing their exercises. Many did not have an adequate grip, difficulties in eye-hand coordination and perceptual problems such as auditive, visual and spatial perception. A high percentage were also over-sensitive to olfactory impression; e.g. they had to smell the food before eating it. Other areas that might cause problems in daily activities are related to difficulties with quickness, planning, memory and attention. This supports what we have seen in our study and the WISC profiles indicate both speed and attention problems in the TS group [26]. We could not address the issue of pure versus ADHD comorbid TS in relation to these deficits. This is particularly salient for children with TS, who most probably have poor school performance, academic and learning problems. These results are consistent with previous studies that have demonstrated deficits in fine motor coordination tests in patients with TS $[5,7,9]$. A striking aspect of the present sample was the high comorbidity (92\%) with other psychiatric conditions, especially with ADHD [3]. In the literature, there exists controversy whether fine motor skill are the results of the neuropathology of the TS disorder $[4,7,9]$ or of ADHD [12]. However the study number of the individuals was too few to be divided into subgroups especially as the children without ADHD were very few $(\mathrm{N}=8)$ [3].

As regards to tic severity and age at onset, we did not find any relation to any of the fine motor or perception ability. However, some relation has been discovered. $20 \%$ of the children displayed developmental coordination disorder and every fifth child pathological movement $A B C$ test. Slow handwriting speed is also observed in $40 \%$ of the children. Slow handwriting speed may reflect interference from several possible sources according to Leslie. This may be due to the arm tics that directly interfere with handwriting or results in a slower overall production rate. Secondly, a child who has OCD or obsessive-compulsive symptoms may have compulsive rituals that interfere with writing. Thirdly, there may be independent visual processing deficits that reduce graphomotor speed. Finally, many of the neuroleptic medications used to treat tics may produce motoric side effects that interfere with handwriting. There are few patients in our group that take neuroleptics (two children). HABBA was chosen as the investigation method. An alternative method could have been. An alternative method could have been AMPS (Assessment of Motor and Process Skills) [27] that assesses motor and process skills in real standardised activities and tests specific cognitive fine-motor skills. However, it was not validated for children at the time of the study. HABBA identified motor, sensory, kinaesthetic functions and visual perception in the frame of Luria's neuropsychological theory 
and was validated for Swedish children. The hand strength in this investigation was measured with the vigorimeter Martin. Because the norms of this instrument are given with a wide range, it was decided to use the normal value given by Cederlund et al. [22]. If Grippit [28] had been used, hand strength would have been determined more exactly. Many of the children are overly flexible in their hand joints. When one has overly flexible joints, one has a greater movement range to steer with every movement. One has to use more force and concentration to be able to get precision in the grip. Many children have overly flexible joints and it can affect their fine motor ability and time for automating the movement pattern. Kadesjö [29] takes up the fact that children do not have sufficient established movement melody. The reason could be that they have not gotten the exercise necessary. Some of them have perhaps avoided everything that they have deemed as difficult. Others have maybe not given themselves time to try new things. Without a well-developed movement melody movements are not automatic. Low muscle tonus also affects their ability to conserve power and energy, good sitting position and their participation in carrying activities.

One fifth of these children have a late-developed hand dominance. Some use both hands interchangeably but then often in different activities. That children choose hand dominance later influences their ability in fine motor activities such as writing. This influences the environment such as the teacher's conception that the children tire easily, become distracted and have a short attention span. This is influenced by the fact that automation of the fine-motor movement pattern is delayed. It can be seen that children who have a deviating pen holding have a slower time in the stick test. The activities are probably not automated or they have had a late development of the automation of the motor writing ability. The hand's fine-motor skill development to attain a normal adult's pen holding, the dynamic tripod pen holding, is reached at the age of seven [16]. Several of the children in this study have a delay in the development of their pen hold. Some of the children have a divergent pen hold. If the children have a divergent pen hold, it is very difficult to teach them to have a dynamic tripod pen hold. They can be informed of a more functional grip and try aids such as pen grips, which are placed on the pen and help to place the fingers in the dynamic tripod position [4]. Children, who don't have an automatic response to fine-motor activities, have to exert themselves very much in order to do the activities so that they lose concentration and attention on the tasks and their execution.

Furthermore, our results indicate that speed problems may characterise children with TS. These findings are along the same lines as the results indicating slow reaction times and cognitive slowing in TS children [27], but the issue of slow processing speed in TS has so far been studied very little. Our last study showed that these children are slower [3].

\section{Conclusion}

Tourette syndrome in children seems to be associated with fine motor, perception and ADL problems. Early interventions to help with fine motor skills of TS symptoms should be undertaken, and in view of TS children, interventions such as an occupational therapist appear necessary.

\section{Acknowledgements}

We are grateful to all parents and children who participated and to Hans Arinell, for excellent guidance in the statistical formation of the data. We also want to thank the Principals of all the Primary Schools of Ludvika/Smedjebacken and habilition centre in Ludvika.

\section{Limitations}

The major drawback is the small sample size, which is a reflection of the population based recruitment procedure. We could not control properly for comorbid conditions. Secondly, no control group was used. Instead we used normative data. However, as the missing data in many cases was due to the failure, despite attempts, to secure valid test results from these very troubled children, it is highly unlikely that the problems of our TS children were inflated - rather, they may have been deflated.

\section{References}

1. Robertson MM (2000) Tourette syndrome, associated conditions and the complexities of treatment. Brain 123: 425-462.

2. Singer HS (2005) Tourette's syndrome: from behavior to biology. Lancet Neurol 4:149-159.

3. Khalifa N, Von Knorring AL (2006) Psychopathology of Tourette syndrome and other tic disorders in a total population of school children. J Am Acad Child Adolesc Psychiatry 45:1346-1353.

4. Packer L (2005) Tic -Related school problems: impact on functioning, accommodation, and interventions. Beh Mod 29: 876-899.

5. Packer L (2007) Educating children with Tourette syndrome: understanding and educating children with a neurobiological disorder.

6. Bloch MH, Sukholsky DG, Leckman JF, Schultz RT(2006) Finemotor skills deficits in childhood predict adulthood tic severity and global psychosocial functioning in Tourette syndrome. J Child Psychol Psychiatry 47: 551-559.

7. Schultz RT, Carter AS, Gladstone M (1998) Visual-motor integration functioning in children with Tourette syndrome. Neuropsychology 12: 134-145.

8. Schuerholz LJ, Cutting L, Mazzocco MM, Singer HS, Denckla MB (1997) Neuromotor functioning in children with Tourette syndrome with and without attention deficit hyperactivity disorder. J Child Neurol 12: 438-42.

9. Shapiro AK, Shapiro ES, Bruun RD, Sweet RD (1978) Gilles de la Tourette syndrome. New York: Raven Press.

10. Bornstein RA (1990) Neuropsychological performance in children with Tourette's syndrome. Psychiatry Res 33: 73-81.

11. Bornstein RA, Baker GB, Bazlewich T, Douglass AB. Tourette's syndrome and neuropsychological performance. Acta Psychiatr Scan 84:212-216. 
12. Harris EL, Schuerholz LJ, Singer HS, Reader MJ, Barun JE, et al. (1995) Executive function in children with Tourette syndrome and/or comorbid anxiety-deficit hyperactivity disorder. J Int Neuropsychol Soc 1: 511-516.

13. Dalby MA, Østergaard JR, Trillingsgaard A (2000) Barn som är annorlunda: hjärnans betydelse för barnets utveckling [Children who are different, the importance or the brain for the development of the child]. Studentlitteratur, Lund. ISBN 91-44-00982-8.

14. Jewers R. Characteristics of Handwriting in the Child with Tourette Syndrome.

15. Chang SW, McCracken JT, Piacentini JC (2006) Neurocognitive correlates of child obsessive compulsive disorder and Tourette syndrome. J Clin Exp Neuropsychol 29: 724-733.

16. Holle B (1987)Barns motoriska utveckling [Motor development in children]. Stockholm: Natur och kultur.

17. Waldrop MF, Halverson CF (1971) Minor physical anomalies and hyperactive behavior in children. In: Hellmuth J, editor. Exceptional Infant: Studies in Abnormalities. New York: Brunner/ Mazel pp: 343-380.

18. Gillberg $C(1980)$ Children with minor developmental disorders. Neurological and neurodevelopmental problems at age 10. Dev Med Child Neurol 27: 3-16.

19. Luria A. Higher cortical function in man. New York: Basic Books.

20. Liorens LA, Levy R, Rubin EZ (1976) The work Adjustment Program: A prevocational experience. Am J Occup Ther Inc.

21. Jacobsson $H$, Sundqvist A (2006) HABBA, Handfunktionsbedömning på barn från 6 år [HABBA, Assessment of hand function in children from 6 years of age].
22. Cederlund R, Runnqvist K, Sollerman C (1999) Handens rehabilitering, volym 1: Undersökning, behandlingsprinciper, behandlingsmetoder [Rehabilitation of the hand, vol 1. Assessment, principles of treatment, methods of treatment]. Lund: Studentlitteratur.

23. Lantz C, Melén K (1992) Finmotorisk utvecklingsstatus 1-7 år: en utvärdering och korrigering av ett tidigare arbete [Developmental status of fine motor ability 1- 7 years: an evaluation and correction of an earlier work]. Stockholms läns landsting, Omsorgsnämnden, PP54.

24. Eliasson AC, Gordon AM, Forssberg H (1995) Tactile control of isometric fingertip forces during grasping in children with cerebral palsy. Dev Med Child Neurol 37: 72- 84.

25. Hubka G, Fulton, Shady G, Champion L, Wand R (1988) Tourette syndrome: Impact on Canadian Family Functioning. Neuroscience and Biobehavioral Review 12: 259-61.

26. Khalifa N, Rydell AM, Dalan M (2010) Tourette syndrome in the general child population: Cognitive functioning and selfperception. Nordic Journal of Psychiatry 64: 11-18.

27. Fisher AG (2003) Assessment of Motor and Process Skills vol II: User Manual. 6th Ed. USA: Three Star Press, Inc. Fort Collins Colorado.

28. Wallström A, Nordenskiöld U (2001) Assessing hand grip endurance with repetitive maximal isometric contractions. J Hand Ther 14: 279-85.

29. Kadesjö B. Barn med koncentrationssvårigheter [Children with concentration problems]. Stockholm: Almqvist \& Wiksell. 